\title{
Las mujeres en aislamiento por COVID-19: Tiempos de cuidado, tareas domésticas, comunitarias y Teletrabajo.
}

\section{Women in Isolation by COVID-19: Care Times, Domestic, Community Tasks, and Teleworking}

\author{
Paola Bonavitta* \\ Gabriela Bard Wigdor
}

\section{Resumen}

Este artículo analiza, desde un enfoque feminista decolonial, la sobrecarga de trabajos del cuidado, domésticos y de teletrabajo que asumen las mujeres durante la pandemia por COVID-19 y en aislamiento social. Metodológicamente se realizó una encuesta y entrevistas semiestructuradas en Argentina, donde se evidencia las sobrecargas de trabajo que asumen las mujeres que no son contempladas por los gobiernos capitalistas y patriarcales, provocando que ellas deban soportar los costos económicos, físicos y psíquicos de la crisis. Se perpetúan las desigualdades de género y clase en la distribución de las tareas, tanto al interior de los hogares, como desde el Estado y el mercado, tornando urgente la redistribución y reconocimiento de estas múltiples jornadas laborales feminizadas.

Palabras claves: Capitalismo, patriarcado, trabajo doméstico y de cuidados, mujeres, aislamiento social.

\begin{abstract}
This article analyzes, from a decolonial feminist approach, the overload of care, domestic and telework jobs that women take on during the COVID-19 pandemic and in social isolation. Methodologically, a survey and semi-structured interviews were carried out in Argentina, where the work overloads assumed by women that are not contemplated by the capitalist and patriarchal governments are evident, causing them to bear the economic, physical and psychic costs of the crisis. Gender and class inequalities are perpetuated in the distribution of tasks, both within households, and from the State and the market, making urgent the redistribution and recognition of these multiple feminized working days.

\footnotetext{
* Investigadora CONICET. Dra. en Estudios Sociales de América latina. Mg. en Sociología y Lic. en Comunicación Social por la Universidad Nacional de Córdoba. Diplomada en Feminismos Políticos por la Universidad Nacional Autónoma de México. Docente e Investigadora de El Telar, Comunidad de Pensamiento Feminista Latinoamericano.

** Doctora en Estudios de Género, Magister y Licenciada en Trabajo Social. Se desempeña como Profesora asistente de la Facultad de Ciencias Sociales de la Universidad Nacional de Córdoba y como Investigadora Asistente del Centro de Investigaciones y Estudios sobre Cultura y Sociedad (CIECS-CONICET y UNC), Argentina. Investigadora de El Telar, Comunidad de Pensamiento Feminista Latinoamericano.
} 
Revista Punto Género N ․ㅜ 15. Junio de 2021

ISSN 0719-0417 / 89-113

Key words: Capitalism, patriarchy, domestic and care work, women, social isolation.

Fecha de recepción: Noviembre 2020

Fecha de aprobación: Junio 2021

\section{Introducción}

En el presente artículo desarrollamos los resultados de una indagación acerca de una temática que hace décadas los feminismos debaten y denuncian: los trabajos de cuidado, el uso del tiempo y el trabajo doméstico, en tanto trabajos feminizados y no reconocidos como tales. En particular, investigamos esta problemática en el contexto de una pandemia mundial, producto del Coronavirus (COVID-19), cuando los gobiernos han tomado medidas que incluyen el aislamiento social, preventivo y obligatorio para toda la población. En efecto, examinamos la vida de mujeres de sectores trabajadores y medios que realizan simultáneamente trabajos de cuidado, doméstico, comunitarios y teletrabajo, como las propias autoras.

En ese sentido, advertimos que nos distanciamos de enfoques positivistas que insisten en la búsqueda de una objetividad en la producción de conocimiento científico asociada al borramiento de la autoría de quienes escriben y a la búsqueda de metodologías que garanticen una neutralidad y/o control sobre "los aspectos subjetivos" de la investigación, considerados una contaminación para el proceso de investigación. Para quienes trabajamos desde epistemologías feministas, advertimos que no existe ciencia neutral u objetiva, que los procesos sociales se investigan desde una posición socioeconómica, racial, etaria, geográfica (entre otras) concretas. Lo objetivo es asumir la posición desde donde miramos el mundo y hacerlo evidente para quienes nos leen. Asimismo, compartimos con Adrienne Rich (2019) que lo extraño es "el autor ausente, la autora que asienta especulaciones, teorías, hechos y fantasías sin ninguna base personal" (p.28). Parafraseando a la autora, lo personal es político, pero no por lo personal en sí mismo, como relato individual, sino como interrogante/respuesta acerca de la realidad del colectivo de mujeres y cuerpos feminizados. Además, sostenemos, desde un enfoque feminista decolonial, la apuesta por una ciencia comprometida con su tiempo, donde ya no se intenta arrojar teorías iluminadoras, vanguardistas o anticipatorias del orden que debería llegar o al que deberíamos apostar, sino que:

Los intelectuales deben aceptarse como intelectuales de retaguardia, deben estar atentos a las necesidades y aspiraciones de los ciudadanos comunes y teorizar a partir de ellas. De lo contrario, los ciudadanos estarán indefensos ante los únicos que saben hablar su idioma y entienden sus preocupaciones. En muchos países, estos son pastores evangélicos conservadores o imanes islámicos radicales, apologistas de la dominación capitalista, colonialista y patriarcal (De Sousa Santos 2020, p. 8) 
En ese sentido, lo que desarrollamos en este trabajo es relevante para la comprensión del tema, tanto para las mujeres afectadas por el aislamiento social obligatorio, como para las propias autoras, mujeres, madres, docentes/investigadoras, con adultas/os mayores a cargo y realizando teletrabajo o trabajo en línea desde hace casi dos años (desde el inicio de la pandemia por el Covid-19). Esta situación, generalizada entre las mujeres que sostienen empleos y trabajos de cuidado en Argentina, nos muestran las sobrecargas laborales que inciden en los usos del tiempo, donde las posibilidades de cuidado sobre el cuerpo y la salud en general de las mujeres se ven gravemente afectadas, así como nos "ofrece información sobre el "reloj cotidiano de la población": lo que las distintas personas realizan durante las 24 horas del día de acuerdo a distintas variables significativas como el género (Carrasco \& Domínguez, 2002). Entre las variables significativas que inciden en este contexto, queremos destacar la explotación de la fuerza de trabajo de las mujeres que implican los contextos de crisis social y sanitaria, donde el Estado descarga responsabilidades de atención de la cuestión social sobre los cuerpos de las mujeres (Federici, 2018).

En relación con las crisis sociosanitarias, nos encontramos atravesadas por la pandemia por el COVID-19 interpretado como «hecho social total», en el sentido de que sacude el conjunto de las relaciones sociales y conmociona a la totalidad de los actores, de las instituciones y de los valores (Ramonet 2020). Por ello los ejes que aquí trabajaremos se relacionan con emergentes de entrevistas y encuestas, donde las mujeres hablan de las sensaciones, experiencias y reflexiones sobre este momento histórico. Sus testimonios son expresiones de subjetividades atravesadas por la pandemia y recuperadas con el valor epistémico y político de una reflexividad colectiva, construida entre autoras y sujetos de la investigación para comprender lo que nos ocurre en la vida cotidiana (Méndez, López, Marcos \& Osorio 2013).

En relación con la situación pandémica, Argentina tomó el COVID-19 como parte de su agenda de gobierno el 3 de marzo del 2020, cuando apareció la primera persona infectada en el país. Rápidamente el gobierno intervino y decretó la cuarentena obligatoria para toda la población. A lo largo de la cuarentena emergieron, no solo los conflictos económicos que acarrea el cese productivo de varias ramas de producción, sino también realidades vinculadas a las problemáticas de género, clase, migración, discapacidad y generación, como aspectos que agudizan la crisis estructural económica y sanitaria.

Argentina se ha vuelto un modelo de cuidado de la salud pública en base a las diferentes políticas de asistencia que implementó el gobierno para atender las necesidades más urgentes de los diferentes sectores afectados por la crisis sanitaria ${ }^{1}$ (plan de vacunación modelo a nivel mundial, IFE, subsidio para salarios a empresas, entre otras). Sin embargo, siendo el Estado, desde su génesis, capitalista y patriarcal, se torna difícil instrumentar políticas concretas para la atención de las necesidades de los cuerpos feminizados y las múltiples violencias heteropatriarcales, como la ausencia de reconocimiento de quienes soportan las principales sobrecargas de trabajo, ajustes

1 "Para más información sobre las medidas implementadas por el gobierno argentino, consultar el siguiente enlace": https://www.argentina.gob.ar/coronavirus/medidas-gobierno 
económicos, padecimientos físicos y psicológicos. Al respecto, Rita Segato explica que el Estado "tiene un ADN patriarcal, su naturaleza es patriarcal, ya que constituye el último momento, la última estructura generada por la historia de la masculinidad" (2019, p. 35). De modo que la propia lógica del orden estatal capitalista, patriarcal y neocolonial supone movimientos de dominación, dependencia y racismo sobre los sectores subalternos como las mujeres. Además, se evidencia la situación de debacle económica y sanitaria que sufre el país, agudizada por los cinco años previos de políticas gubernamentales de achicamiento del gasto público y de anulación de conquistas sociales durante la anterior gestión política (gobierno del Pro-Cambiemos, presidente Mauricio Macri).

Asimismo, el neoliberalismo se instaló con fuerza en el mundo en la última década y sus consecuencias se hacen evidentes en este tiempo de fragilidad social. Como señala De Sousa Santos (2020), la pandemia agudiza la crisis a la que ha sido sometida la población por el capitalismo neoliberal, incapacitando al Estado para responder con políticas públicas activas y eficaces. Se evidencia que la cuarentena, así como cualquier medida que se pretenda universal, es discriminatoria, porque no contempla casos singulares, como la realidad de que resulta más sencillo para las clases asalariadas formales y propietarias poder respetarla y así cuidar su salud sin padecer miseria y hambre. Tampoco esta medida considera la existencia de personas que enfrentan la imposibilidad del aislamiento, ya sea por pertenecer al sector de cuidadoras/es -como médicos/as, enfermeras o a servicios esenciales como el transporte público, recolección de la basura, entre otros-, por salud mental o por no contar efectivamente con un espacio físico donde habitar y permanecer.

En consecuencia, la cuarentena no atiende a problemáticas de clase ni de género, siendo los sectores populares, las mujeres y cuerpos feminizados aquellos grupos humanos que encuentran especialmente difícil el aislamiento. Actualmente, cerca del $60 \%$ de las mujeres de todo el mundo trabajan en la economía informal, ganan menos, ahorran menos y corren un mayor riesgo de caer en la pobreza (ONU, 2020). Por ello, focalizar en la situación de las mujeres también nos permitirá pensar políticas públicas que las pongan en el centro de la cuestión.

Desde la división sexual del trabajo, son las mujeres quienes se ocupan principalmente de los cuidados dentro y fuera de sus hogares. Por ello, otro de los ejes que aquí consideramos son los trabajos de cuidado, domésticos y comunitarios que históricamente han quedado relegados a las mujeres. En el contexto de pandemia, la ONU afirma que "al tiempo que pierden sus empleos remunerados, el trabajo de cuidados no remunerado de las mujeres ha aumentado de forma exponencial debido al cierre de las escuelas y la mayor necesidad que tienen ahora las personas mayores" (ONU, 2020, p.1). Además, el informe de las Naciones Unidas sostiene que esas tendencias se están conjugando como nunca para aplastar los derechos de las mujeres y negarles sus oportunidades (ONU, 2020):

La pandemia del COVID-19 ha dejado más claro que nunca que el trabajo doméstico no remunerado de las mujeres está subvencionando tanto los servicios públicos como los beneficios privados. Este trabajo debe tenerse en cuenta en los datos 
económicos y en la toma de decisiones. Todos saldremos ganando si existen mecanismos laborales que reconozcan las responsabilidades relacionadas con el cuidado de las personas y modelos económicos inclusivos que valoren el trabajo en el hogar (ONU 2020).

Por tanto, no podemos analizar el orden capitalista si consideramos solo las tareas consideradas tradicionalmente como productivas y obviamos las de cuidado y reproducción social. Como señala Varela (2020), el trabajo doméstico es una unidad no diferenciada del capitalismo y son de relevancia vital para el sostenimiento de este. Son las mujeres quienes representan la fuerza de trabajo mayoritaria en este tipo de trabajos socialmente necesarios en todos los contextos.

Como sabemos en relación con los cuidados, si algo los caracteriza es que se trata de un ámbito siempre atravesado por el género, pues su distribución recae generalmente en las mujeres (Jelin, 2013; Batthyány, 2010; Arriagada \& Todaro 2012). En Argentina, la distribución de los trabajos de cuidado y doméstico es muy desigual: a nivel nacional las mujeres dedican el doble de tiempo a las tareas domésticas y de cuidado, como limpiar la casa, cocinar o cuidar a los niños (Ministerio de Economía, 2020).

Shahra Razavi (2007), por su parte, considera que el cuidado es un trabajo dirigido a personas con dependencia, pero también a los/as adultos/as autónomos/as, quienes serían generalmente hombres. Sira del Río (2004) los refiere como "dependientes sociales", y sostiene que la inmensa mayoría de varones son dependientes, porque no tienen ni la formación para cuidarse, ni el interés en hacerlo, lo cual acentúa la precariedad en el colectivo de las mujeres.

En ese marco, decidimos indagar sobre los trabajos de cuidado y domésticos en tiempos de cuarentena, conocer cómo se experimentaba este momento desde la voz de las protagonistas. Para ello, recurrimos a la metodología cualitativa y cuantitativa, siendo los ejes que organizan la exposición de los resultados el uso del tiempo, las emociones y subjetividades en contextos de pandemia, los trabajos domésticos y los comunitarios.

Prioritariamente trabajamos con una encuesta virtual de muestreo no probabilístico, que arrojó datos acerca de las vivencias sobre el trabajo de cuidado, el tiempo de ocio y las responsabilidades desiguales en tiempos de cuarentena y de teletrabajo. En segundo lugar, hicimos entrevistas focalizadas a personas que están cuidando en tiempos de pandemia y, finalmente, trabajamos con análisis de contenido de discursos publicados en redes sociales, intervenciones de personas que intercambian sobre el tema y noticias en medios de comunicación gráficos y radiales.

Finalmente, reflexionamos sobre la vigencia de la demanda de redistribución y reconocimientos de los trabajos de cuidado, domésticos y comunitarios, en tanto trabajos que garantizan la reposición de la fuerza de trabajo y su bienestar, además de la sustentabilidad de la vida en general. 
Revista Punto Género N ․ㅜ 15. Junio de 2021

ISSN 0719-0417 / 89-113

\section{Metodología}

Epistémicamente, una investigación feminista parte de la premisa de que la desigualdad de género es un aspecto central del orden capitalista, así como que la ciencia dominante reproduce principios sexistas y androcéntricos, por lo que resulta fundamental visibilizar e historizar estos fenómenos para desarmarlos (Castañeda, 2012). Para lo cual, se torna urgente caracterizar los problemas que afectan a las mujeres y cuerpos feminizados, vincularlos de modo constante con el movimiento social o el activismo para construir "puentes, líneas de comunicación y de articulación entre las distintas modalidades y formas de expresión del feminismo" (Castañeda 2012, p. 43). Por ello, investigadoras feministas eligen escenarios de estudio, tanto como personas sujeto de investigación, vinculadas y atravesadas por problemáticas comunes $u$ afines. En consecuencia, la presente investigación nos atraviesa como autoras y como cuidadoras, porque si bien el virus del COVID-19 afecta principalmente a adultos/as mayores, personas con patologías previas y sectores con padecimientos físicos resultado de malnutrición y enfermedades mal curadas, nadie se encuentra exento del riesgo de enfermar, por lo que familias enteras permanecen en cuarentena preventiva obligatoria y al cuidado mayoritariamente de mujeres de todos los sectores sociales.

En otro orden, para esta indagación, las técnicas de obtención de información no se predefinieron de modo unilateral, sino más bien se plantearon como una caja de herramientas (Benet, Merhy \& Pla, 2016), desde donde formulamos interrogantes a la vida diaria en aislamiento. Recurrimos a técnicas propias de la metodología cuantitativa como a otras pertenecientes a la metodología cualitativa.

En primer lugar, tanto la encuesta virtual como las entrevistas y los datos obtenidos de otras fuentes fueron organizados en torno a tres ejes: 1) Uso del tiempo, 2) Emociones y subjetividades en contextos de pandemia y 3) Trabajos domésticos y comunitarios. Esto tuvo que ver con nuestra intención de indagar acerca de cuáles son los tiempos disponibles de las mujeres y cómo estos se distribuyen, así como la realización de trabajos domésticos y comunitarios en sus vidas cotidianas. A esto, le sumamos el interés por indagar en las subjetividades y emocionalidad de las vivencias particulares en contexto de pandemia.

La encuesta en particular se efectuó de modo virtual y circuló en Argentina, entre personas que realizan trabajos de cuidado durante la cuarentena. Se hizo un muestreo no probabilístico dado el contexto de producción y sus particularidades, donde respondieron 555 personas. El cuestionario se focalizó en indagar en los trabajos de cuidado y teletrabajo. El mismo contó con preguntas abiertas y preguntas cerradas de opción múltiple. Asimismo, recurrimos a indicadores macro estadísticos y de organismos oficiales nacionales que nos han permitido enriquecer nuestros resultados.

En segundo lugar, implementamos entrevistas focalizadas a mujeres que mostraron interés en ampliar información acerca de la encuesta, a través de videollamadas, llamadas telefónicas y chats virtuales, aplicando los recursos tecnológicos a la investigación feminista. En total, se entrevistaron a 10 mujeres que ya habían respondido la encuesta con anterioridad, para profundizar sobre algunos aspectos. El 
criterio de selección fue estratégico, buscando que se encuentren empleadas en el ámbito público y privado, en diferentes rubros y con composiciones familiares diversas.

Finalmente, en el escrito emergen trazos de la autoetnografía, en tanto técnica que permite focalizar en las "tensiones y paradojas que tienen lugar durante el quehacer investigador cuando éste se dirige a captar con profundidad la experiencia humana, social y culturalmente mediada" (Guerrero Muñoz, 2014). La autoetnografía se basa en la perspectiva epistemológica (Ferraroti [1983] 1988) que sostiene que una vida individual puede dar cuenta de los contextos en los que vive la persona en cuestión, así como de las épocas históricas que recorre a lo largo de su existencia (Blanco, 2012). Como trabajadoras de la ciencia y de la educación, mujeres, madres y cuidadoras, este estudio nos atraviesa corpo-afectivamente y hace parte de las reflexiones que atraviesan toda la escritura como el análisis de los datos.

\section{Resultados}

Durante la última semana de marzo y la primera de abril del presente año 2020, realizamos una encuesta denominada "Cuidados, usos del tiempo y trabajos en cuarentena". Se tomó una muestra de 555 personas, de las cuales el 88,6\% fueron mujeres que superan los 30 años. De ese total, más de la mitad (63\%) tiene estudios universitarios y de posgrado, el $29 \%$ universitario completo, el $21,5 \%$ posgrado completo y el $13 \%$ posgrado incompleto. Por tanto, estamos hablando de mujeres que cuentan con capitales culturales, simbólicos y económicos que las posicionan con derechos que se traducen en privilegios frente a otras mujeres que se encuentran en desventaja en este contexto latinoamericano.

En ese sentido, en las entrevistas realizadas con 10 mujeres que también respondieron la encuesta, la sobrecarga de trabajo se percibe ahora con mayor intensidad, porque el trabajo doméstico y de cuidados que solían socializar con otras mujeres como abuelas, tías o pagando horas a empleadas domésticas, son ahora efectuados por ellas mismas. En efecto, a las horas que dedicaban al empleo se agregan, simultáneamente y en un mismo espacio, las demandas domésticas y de cuidado que solían asumir otras mujeres. Lo que evidencia las desigualdades entre las mismas mujeres y nos advierte que el género es interceptado por otras dimensiones como la clase, generando posiciones más o menos ventajosas en el orden social.

Asimismo, el 58\% de quienes respondieron la encuesta son empleadas formalizadas, lo que delimita la muestra a un universo muy específico de la sociedad argentina, especialmente entre quienes poseen educación superior, pueden realizar teletrabajo y cuentan con un salario fijo. Asimismo, de este grupo, el 71,3\% trabaja en relación de dependencia, detallando, el $26 \%$ en gobiernos provinciales, el $23 \%$ en empresas privadas, el $22 \%$ para el gobierno nacional y el $10 \%$ para los gobiernos municipales. Todas estas personas realizan teletrabajo o trabajo virtual desde su domicilio durante la cuarentena. Además, los trabajos de cuidado y domésticos recaen sobre las mujeres que, como señalamos, representan al $88,6 \%$ de la población total de la encuesta. 
Como advertimos en estas cifras, el cuidado en todos sus órdenes descansa en los cuerpos feminizados, entendiendo a estas tareas como producción física y subjetiva. Como sostienen Benet, Merhy y Pla (2016), el trabajo de cuidado es esfuerzo vivo en acto y se produce en los encuentros entre las personas que participan de su producción. "No puede prefabricarse ni estereotiparse porque se rige por lo que ocurre y circula entre las personas implicadas" (p.15). De manera que definimos a la dimensión de los cuidados como un espacio relacional donde pueden generarse procesos de acogida, vínculo y responsabilización (Merhy, 2006), tanto como tareas permanentes e invisibles para el Estado y los mercados, que lindan con la explotación. Este último aspecto se refleja en la encuesta, donde la mayoría de las mujeres dice sentirse exhausta y sin tiempos para descansar.

Para ordenar el análisis de los resultados que presentamos, tanto de entrevistas, encuestas y otros datos obtenidos, organizamos cuatro puntos centrales de lectura: 1) usos del tiempo, 2) emociones y subjetividades en contextos de pandemia y 3) trabajos domésticos y 4) trabajos comunitarios.

1) Usos del tiempo: trabajos constantes

En relación con el uso del tiempo que realizan las mujeres, más de la mitad de las encuestadas percibe que durante la cuarentena se dedica a las tareas domésticas y de cuidado "las 24 horas del día" y que no dispone de tiempo para descansar. La percepción del tiempo se expresa en una sensación física y psíquica de permanente o constante carga laboral y de cuidados. Estas mujeres encuentran que sus rutinas han sido alteradas en cuarentena, porque ya no existe alternancia con otras personas para el cuidado de otras/os y por el cambio de escenario laboral que implica pasar de la oficina, el comercio o el aula a la mesa de la cocina, el cuarto o donde pueda dedicar unas horas al teletrabajo, siendo interrumpidas de modo constante por otras demandas domésticas.

\section{Gráfico 1: Horas dedicadas al cuidado de personas en cuarentena.}

¿Cuántas horas considera que cuida, atiende, se ocupa de otras personas durante la cuarentena?

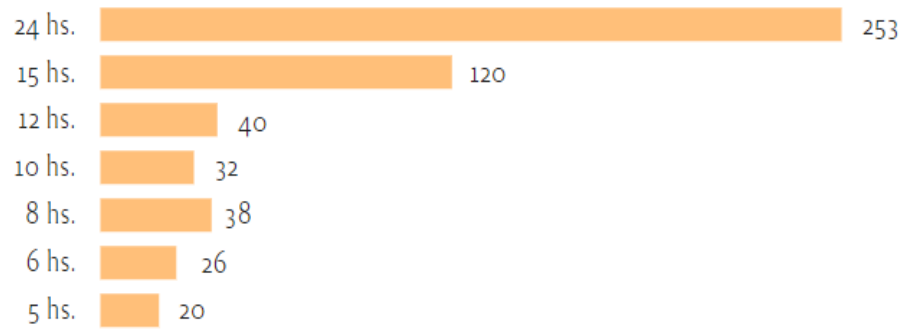

Fuente: Resultados de la encuesta virtual realizada por las autoras en abril del año 2020 en Argentina

En consecuencia, durante este tiempo de aislamiento social obligatorio, el empleo, el trabajo doméstico y de cuidados junto a las tareas comunitarias, se tornan un solo tiempo de trabajo en simultáneo. Lo que los estudios de género llaman como la primera, 
segunda y tercera jornada laboral (Carrasco, 2001), son ahora un mismo tiempo de trabajo simultáneo y desordenado:

Me levanto, le doy de desayunar a Simón, prendo la compu y respondo correos mientras hago la leche y esas cosas. Le pongo un rato de tele para hacer zoom y después hacemos tareas. Llega el almuerzo entre llamadas telefónicas del trabajo, el pendejo que quiere jugar todo el tiempo y llora...a la siesta mientras juega limpio la casa, salgo a hacer compras y sigo con el bendito teletrabajo. También sostengo una red sorora donde atendemos mujeres en crisis emocional, es una red de psicólogas feministas (E1, Comunicación personal, 5 de mayo del 2020).

Como advertimos en este testimonio, no existe un orden espacial ni temporal para atender las múltiples responsabilidades que supone el aislamiento social obligatorio resultado de la pandemia. La vida cotidiana se ve afectada de modo total, no encontrando las mujeres políticas públicas ni estrategias colectivas para abordar las innumerables demandas familiares, laborales y comunitarias que afectan, además, los tiempos de descanso, ocio y recreación.

En ese sentido, el $50,5 \%$ de las encuestadas considera que el descanso no aumentó durante la cuarentena, al contrario, el cansancio empeoró debido a la sobrecarga laboral, a la sensación de angustia que produce este contexto, que no contribuye a la concentración, relajarse o la potencia necesaria para nuevos aprendizajes.

\section{Gráfico 2: ¿Aumentó el tiempo que dedica a actividades de ocio y recreación?}

¿Siente que ha aumentado el tiempo que se dedica a realizar actividades que le gustan a usted o que le recrean?

457 respuestas

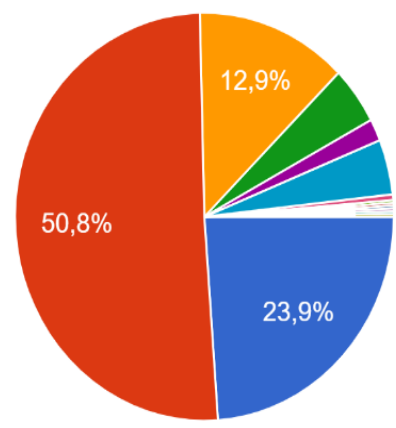

SI, aumentó

No, no aumentó

Tal vez

No aumentó, pero siento que si

Aumentó, pero no lo siento pesado

Está igual

Disminuyó

No

$1 / 2 \nabla$

Fuente: Resultados de encuesta virtual realizada por las autoras en abril del año 2020 en Argentina

Estos resultados necesitan confrontarse con los discursos mediáticos, del mercado y la sociedad de consumo, así como de la denominada psicología del coaching, que nos ofertan e impulsan a dedicarnos a nuevas actividades físicas, recreativas 0 de aprendizaje. Advertimos cómo se multiplican ofertas ilimitadas de actividades para hacer 
online $^{2}$ (yoga, deportes, danza, idiomas, talleres literarios, culinarios, etcétera), cuando los tiempos reales de las personas parecen achicarse y no extenderse. En efecto, el total de las entrevistadas dicen que el tiempo de disfrute no ha crecido, mientras que sí ha aumentado la ausencia de tiempos para el descanso y el ocio. Asimismo, en la encuesta el $65 \%$ afirmó estar más cansada que antes de la cuarentena y el $70 \%$ dijo trabajar más que antes.

\section{Gráfico 3: ¿Siente que trabaja menos que antes de la cuarentena?}
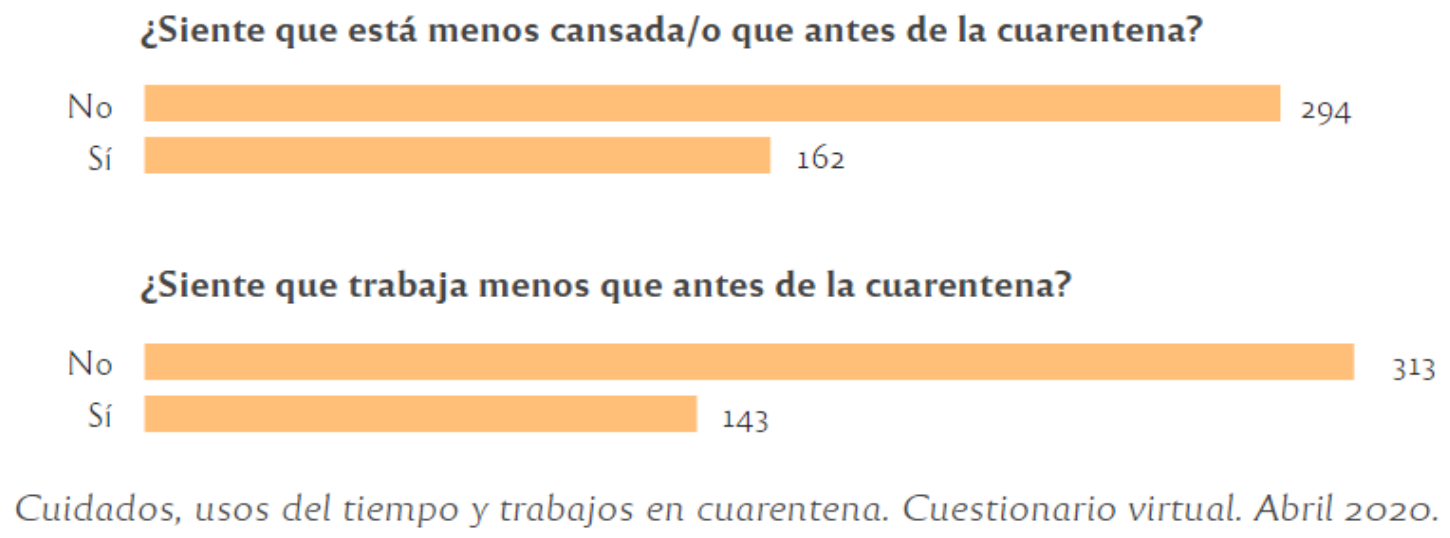

Fuente: Resultados de la encuesta virtual realizada por las autoras en abril del año 2020 en Argentina.

Las exigencias del empleo no han cesado, al contrario, han aumentado debido a la necesidad de mantener el sistema educativo funcionando, tanto como las empresas continuar vendiendo, solicitando de las trabajadoras aprendizajes de nuevas destrezas para desempeñarse en el universo virtual sin capacitación previa, ni pago por las horas extras que implica aprender a usar las tecnologías de Información y Comunicación (TICs):

Yo le dije al gremio que no puedo hacer un curso acelerado de aula virtual y de zoom para atender a todo. Encima en mi casa tenemos una sola computadora que comparto con mis tres hijas... no sé cómo creen que puedo estar frente a la pantalla tanto

${ }^{2}$ Consultar los siguientes ejemplos: "Tiempo libre y productivo. Diez cursos online de idiomas para aprovechar en cuarentena". Disponible en: https://www.clarin.com/tecnologia/cursos-onlineidiomas-aprovechar-cuarentena 0 iFTtdRBYF.amp.html

“¿Cómo no dejar de ejercitarse en estos tiempos de coronavirus? El ejercicio puede ayudar tanto para evitar el tedio como para fortalecer el sistema inmunológico". Disponible en: https://www.eltiempo.com/vida/como-no-dejar-de-ejercitarse-en-estos-tiempos-de-coronavirus-

475742https://www.clarin.com/tecnologia/cursos-online-idiomas-aprovecharcuarentena 0 iFTtdRBYF.amp.html

Coronavirus. Cenas virtuales, clases de yoga y llamadas a diario: cómo ayudar a los mayores que viven solos. La Nación. 21 de marzo de 2020. Disponible en: https://www.lanacion.com.ar/sociedad/coronavirus-adultos-mayores-virtuales-telefono-nid2345781 
tiempo... estoy saturada de la virtualidad, no me dediqué a la docencia para esto (E2, Comunicación personal, 23 de abril del 2020)

En las entrevistas se evidencia que algunas instituciones intentan persistir en un ritmo de normalidad, sosteniendo la productividad de sus empleadas, sin contemplar las nuevas condiciones cotidianas de trabajo.

Los discursos de productividad también atraviesan a las academias universitarias y de investigación. El mantra neoliberal de "tú puedes" llega a todos los rincones del país vía redes sociales. Una entrevistada comentaba acerca de un grupo de WhatsApp de su instituto de investigación dependiente del CONICET-Argentina:

El otro día me pasaron la foto de Newton como ejemplo de lo que debo ser como cientista en este momento, no es chiste... están en las redes de Conicet con eso de que Newton hizo sus aportes a la ciencia en confinamiento durante la peste...onda que podés ser más productiva en este encierro, me parece tétrico (E3, Comunicación personal, 15 de mayo del 2020).

También estudios como el de Ranzani (2020) muestran que la cultura de la productividad permanente se normaliza y produce efectos perjudiciales para el cuerpo y la salud mental. Incluso, muchas de las entrevistadas creen que lo que consideran "escasa productividad" se vincula con una mala gestión del tiempo personal. Pese a señalar las múltiples cargas laborales que desempeñan a diario, intentan sostener el ritmo productivo en un tiempo de incertidumbre y desconcierto. La culpabilización personal por no poder cumplir con todo lo que se espera de ellas es un ejemplo más de los discursos meritocráticos que se siguen difundiendo en estos tiempos.

En relación con esto, Gómez Rubio, Ganga León y Rojas Paillalef (2017), sostienen que en Latinoamérica se da un predominante maternalismo que idealiza a las mujeres en tanto madres y cuidadoras. Este maternalismo exalta la diferencia entre hombres y mujeres en términos de sus capacidades, reforzando la división sexual del trabajo; donde los cuidados suelen ejercerse por una obligación social y de género, que nos lleva a una dimensión normativa de los cuidados dada por quién debe cuidar, a quién debe cuidar, y por qué debe hacerlo. En efecto, la presión social lleva a las mujeres a aceptar el cuidado como parte de sus atribuciones de género, implicando incluso el sacrificio de los intereses propios.

Para Mabel Burin las mujeres con dobles y triples jornadas de trabajo se sienten deprimidas, se critican por sentimientos de inutilidad, "autoculpabilización, sensación de haber perdido una valiosa guía laboral, teñido de tristeza y desesperanza, con sus implicaciones que consisten en que su salud mental queda afectada, así como en una detención en su desarrollo laboral" (2012, p.5). Todo lo cual se agudiza durante la pandemia, que no sólo aumenta las horas de trabajo y cambia los espacios donde se desarrollan (del público al ámbito íntimo), sino que también desafía a nuevas convivencias entre familias, aceptación de ausencias afectivas significativas, problemas económicos y efectos psicológicos del encierro. 
Revista Punto Género N.․ 15. Junio de 2021

ISSN 0719-0417 / 89-113

2) Emociones y subjetividades en contextos de pandemia

Como resultado de las preguntas referidas a las sensaciones o emociones durante la cuarentena, la mayoría afirmó sentirse mentalmente cansada/o (48\%) y angustiada/o (36,5\%), mientras que solo el $3 \%$ afirmó sentirse despreocupada/o.

\section{Gráfico 4: ¿Con qué estados de ánimo se siente identificado/a?}

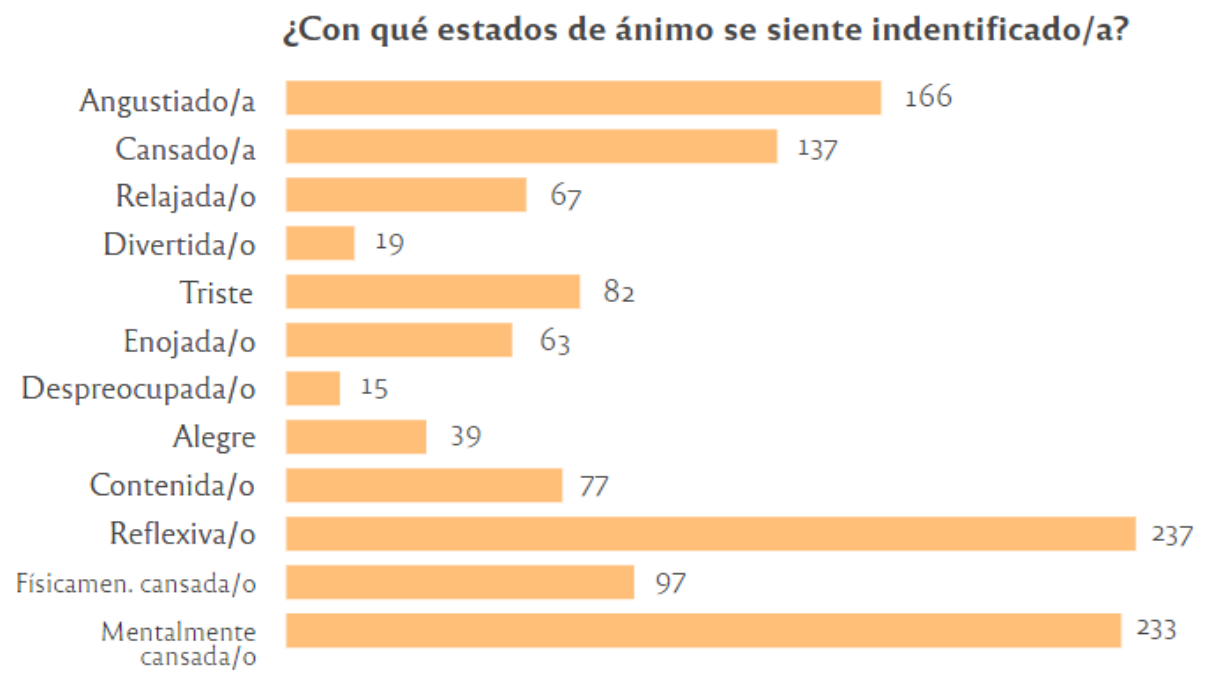

Cuidados, usos del tiempo y trabajos en cuarentena. Cuestionario virtual. Abril 20

Fuente: Resultados de la encuesta virtual realizada por las autoras en abril del año 2020 en

Argentina

En relación con las preocupaciones, la mayoría sostuvo que el sistema de salud argentino y el cuidado de la familia son dos de sus principales inquietudes durante la pandemia. En tercer lugar, se encontraba la situación económica. El orden de los malestares que expresan las encuestadas describe lo que mencionamos al inicio del artículo sobre el sector social que respondió la encuesta, mayoritariamente mujeres con salarios formales y personas cuya salud se encuentra a su cargo.

Indagamos también sobre cómo se encontraban sus cuerpos en relación con la vivencia forzosa del aislamiento. Al respecto, el 30\% -la mayoría- respondió que estaba tensionada y el $17 \%$ que sentía el cuerpo cansado. Solamente el $18 \%$ sostuvo que el cuerpo estaba exactamente igual que antes de la cuarentena y cuando analizamos en detalle las respuestas, correspondían a respuestas prioritariamente de varones. Aspecto que evidencia el modo en que la distribución de las tareas y del cuidado sigue siendo desigual en términos de género. Incluso en los hogares donde viven dos adultos/as que pudieran socializar los trabajos, son las mujeres quienes se ocupan en la mayoría de los casos. 
Revista Punto Género N.ำ 15. Junio de 2021

ISSN 0719-0417 / 89-113

Gráfico 5: ¿Cómo siente su cuerpo durante la cuarentena?

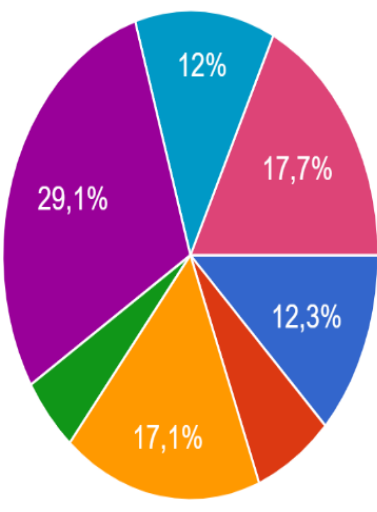

Relajado

Dolorido

Cansado

Flexible

Tensionado

Pesado

Me siento igual que antes de la

cuarentena

Fuente: Encuesta Virtual realizada por las autoras, abril del año 2020, Argentina

La feminización de la responsabilidad produce que las mujeres deban cargar con las tareas del hogar y es por eso que ellas se encuentran gerenciando sus hogares, desde las compras en cuarentena, el aseo minucioso de cada espacio de la casa o el control sanitario sobre el resto de quienes conviven bajo el mismo techo, lo que se traduce en 4 horas más de trabajo doméstico diario, sumado al teletrabajo constante. Según Chant (2005), la feminización de la responsabilidad sugiere la necesidad de considerar de qué modo las mujeres se encuentran cada vez más en el "frente de batalla", y como la carga de la supervivencia familiar recae de manera desproporcionada sobre ellas. Rescatar la dimensión de la feminización de la responsabilidad, de acuerdo con la autora, tiene como objetivo transmitir la idea "de que las mujeres se encuentran asumiendo una mayor responsabilidad en hacerle frente a la pobreza" (Chant, 2005, p. 214) y que esta responsabilidad es invisibilizada, y en muchos casos instrumentalizada por organismos que diseñan políticas públicas para enfrentar la pobreza.

El feminizar las responsabilidades es una realidad que afecta a las mujeres encuestadas, a quienes podríamos caracterizar como independientes, tanto en lo económico como en lo social, pero que siguen siendo destinatarias de las mayores cargas familiares, evidenciando que la explotación de las mujeres en el trabajo de los cuidados son aspectos claves para comprender la subalternidad de género.

Asimismo, lo que hemos desarrollado como sobrecarga física, implica también una carga mental y se constituye en "plusvalía emocional" que las familias obtienen de las mujeres. En efecto, Anna Jónasdottir (2011) explica que la "plusvalía emocional" nombra la apropiación que los hombres realizan de los cuidados y del amor de las mujeres, ya sea por usufructo directo o a través de sus hijas/os. La autora señala que, así como en el sistema capitalista los productos realizados por las/os trabajadores/as se tornan una 
mercancía resultado del trabajo alienado que se apropia el empresariado, la autoridad masculina se basa en la acumulación del amor, el afecto y las emociones feminizadas que se encuentran también alienadas en nombre del amor:

Es agotador, acá los dos hacemos teletrabajo, pero a la que le dice "má tengo hambre, má tengo ganas de hacer pís, má estoy aburrido" es a mí...él sigue en su zoom como si nada, encima si le decís algo te responde que los chicos te lo pidieron a vos (E4, Comunicación personal, 17 de mayo del 2020).

Cuando hablamos de que las mujeres viven días de explotación física y emocional, nos referimos a lo que el fragmento de entrevista muestra en relación con el uso constante que otros hacen de las energías físicas y psíquicas de las mismas. Al respecto dice Jónasdottir (1994) que la explotación expone una relación de intercambio entre personas socio sexualmente situadas, "donde algo sustancial, significativo, es dado y recibido, ganado y perdido, usado-disfrutado por ambas partes, en un proceso productivo de un crecimiento (desigual)" (Jónasdóttir, 1994, p.95).

Como muestra la encuesta que efectuamos, son las mujeres quienes entregan tiempo y trabajo que las obliga a sacrificar entre otras dimensiones, tiempo de ocio o sueño:

Las responsabilidades domésticas y de cuidado aparecen como una tensión para las mujeres (y no para los varones) que buscan resolver ajustando los tiempos (particularmente de descanso y esparcimiento, y también de trabajo remunerado). Esto tiene implicancias evidentes en la posibilidad de las mujeres de una plena participación económica ( $y$ el consiguiente acceso a ingresos propios razonables), y en su calidad de vida (Rodríguez Enríquez 2014, p.22).

En efecto, el $49 \%$ de las encuestadas duerme entre 5 y 7 horas por día durante la cuarentena, es decir que no llega a dormir el tiempo médico sugerido de 8 horas. Acompaña las escasas horas de sueño, dolores de espalda y cuello debido al sedentarismo del teletrabajo, así como el deterioro anímico resultado de cuerpos comprometidos con múltiples trabajos, asumiendo tiempos de incertidumbres y cuidados permanentes.

3) Trabajos domésticos: "Todo el día limpiando y cocinando"

En relación con los trabajos domésticos, las mujeres expresaron que se encuentran "todo el tiempo limpiando y cocinando". Así también marcaron que no veían mejoras en el orden o limpieza de sus casas, incluso cuando la dedicación a estas tareas se incrementó significativamente. 
Revista Punto Género N ․ㅜ 15. Junio de 2021

ISSN 0719-0417 / 89-113

\section{Gráfico 6: ¿Qué actividades de cuidado realiza diariamente?}

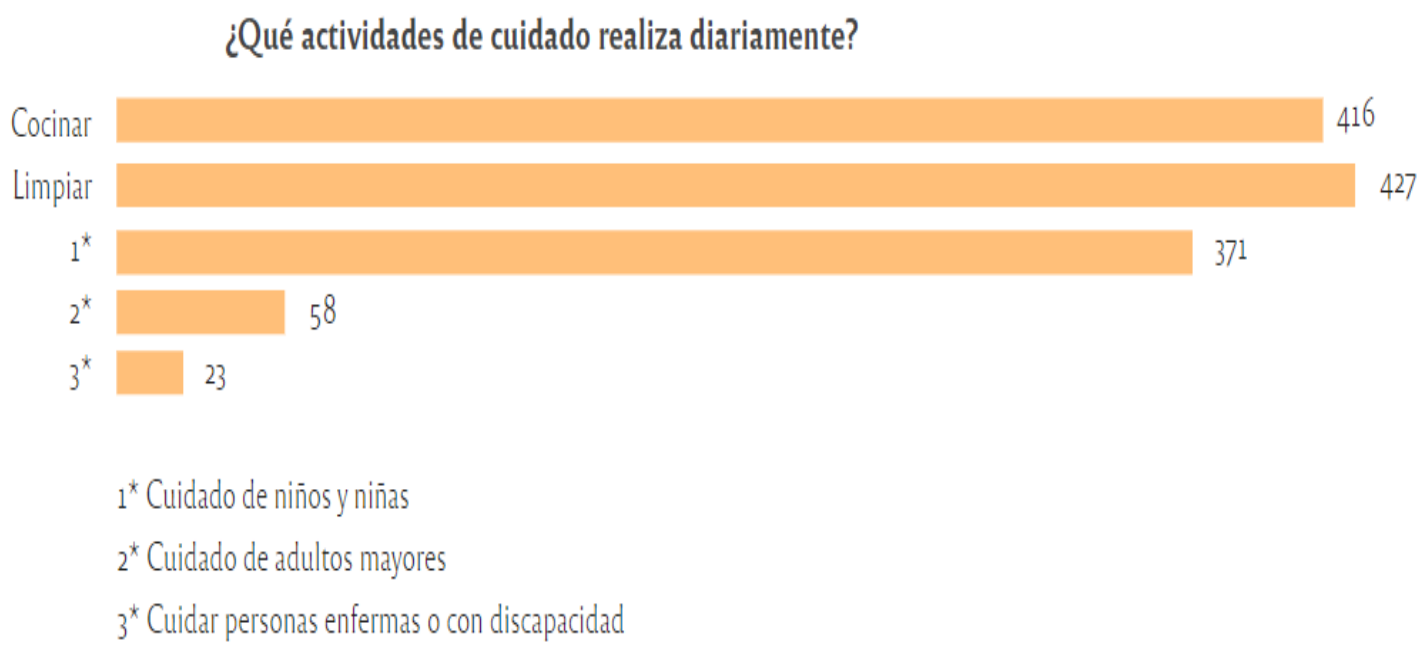

Fuente: Encuesta Virtual realizada por las autoras, abril del año 2020, Argentina

En los espacios destinados para preguntas abiertas en la encuesta, escribieron que se sentían agotadas, con malestar y hastío; así como también reconocieron que cambió su percepción sobre el trabajo doméstico. Algunas de las respuestas textuales que dieron fueron:

"Estoy todo el tiempo en casa" (...) "Una necesita salir y hacer otras actividades...crecer en lo emocional e intelectual" (...) "No creo que a nadie le guste todos los días hacer las tareas del hogar y que eso encima no se valore como trabajo" (...) "Hace ya varios años que he tomado conciencia de la gran importancia y valor del trabajo doméstico, y con la cuarentena solo se confirma más aún" (...) "Me di cuenta que realizar las tareas del hogar todos los días se vuelve cansador y monótono" (Respuestas anónimas en la encuesta virtual realizada, abril del 2020).

La monotonía, el cansancio, la percepción de estar todo el tiempo reiterando actividades que nunca se acaban tienen que ver con el estudiado "síndrome de ama de casa". Al respecto, Betty Friedan (2016) hablaba ya en los años 60 sobre el "malestar que no tiene nombre"3, donde la autora mencionaba los síntomas de inquietud, insatisfacción, angustia y falta de deseo que aquejaba a las mujeres de clase media blancas de la época. En Argentina, Burin (2013) menciona "la neurosis del ama de casa", consistente en la frustración de las mujeres por verse confinadas al escenario doméstico, bajo el mandato de sostener la armonía del hogar como tarea naturalmente propia, limpiar y contener emocionalmente a los y las miembros de la familia.

${ }^{3}$ En el clásico texto "La Mística de la Feminidad", Friedan denuncia un malestar que afectaba a la madre/esposa en los años 60 , debido al encierro doméstico y la soledad de la familia nuclear. 
4) Trabajos comunitarios: alianzas entre mujeres posicionadas desigualmente

Como advertimos en entrevistas, encuestas, posteos en redes sociales, llamados telefónicos y el constante diálogo tejido entre mujeres de diferentes sectores socioeconómicos, la cuarentena obliga a un distanciamiento de los vínculos y aumenta la sensación de soledad. Empero, las mujeres persisten en sostener redes comunitarias y emergen estrategias colaborativas para este momento de fuerte restricciones económicas y necesidades familiares.

En ese sentido, mientras las mujeres profesionales, trabajadoras y universitarias se organizan para garantizar alimentos, asistencia y compañía a las mujeres de diferentes comunidades populares de Argentina, estas últimas organizan comedores, reparten mercadería y se contactan con los gobiernos de modo de solicitar ayuda para sus comunidades:

Me acaba de llamar la chica venezolana, está por parir sola, sin plata para pañales, ni ropa, ni nada (...) me está hablando y esta con contracciones, los ruidos de las contracciones y ocupándose de ver en que CBU recibir dinero. Quiero llorar (...) Va a parir al neonatal, ahí hablé, no tiene DNI, por eso no le dan bola en la Municipalidad (Comunicación personal por whatsapp entre las autoras en el marco de una estrategia colectiva de asistencia a mujeres de sectores populares, 6 abril del 2020 a las 20hs)

En este solo fragmento de un diálogo entre las autoras, podemos advertir el modo en que se anuda el género, la clase y la migración, en tantos aspectos que profundizan las desigualdades que vivimos en este sistema capitalista y patriarcal. En efecto, la política de confinamiento obligatorio, que se pretende una medida uniforme para el conjunto de la población, afecta de modos diferente y desigual a las mujeres y cuerpos feminizados, porque agudiza los conflictos por la sobrevivencia, la necesidad de empleo e incluso la violencia de género. De hecho, los casos de violencia en Argentina han aumentado debido al aislamiento social obligatorio ${ }^{4}$, siendo la cuarentena una frontera entre la vida y la muerte. Así también, se incrementó la percepción de las violencias de género en un 84,6\% (Bidaseca, Aragão Guimarães Costa, Brighenti y Ruggero, 2021). Aun cuando los estados provinciales ponen en marcha mecanismos para prevenir las violencias de género y los femicidios, los agresores ejercen violencias múltiples y las mujeres sienten que sus cuerpos "son-para-otros" (Basaglia, 1983).

Asimismo, el aislamiento en cuarentena evidencia la calidad de vida de las mujeres de sectores populares, obligadas a convivir en casas de dimensiones pequeñas, con crianzas que se mueven en un solo cuarto día tras días, hora tras horas. Donde el ahogo no es sólo económico, es anímico e impacta física y psíquicamente en los cuerpos. Dice una compañera de un barrio popular de la ciudad de Córdoba:

\footnotetext{
${ }^{4}$ Durante la cuarentena en Argentina aumentaron en 18\% las llamadas por violencia de género según datos del Ministerio de las Mujeres, Géneros y Diversidad (Ministerio de las Mujeres, Género y Diversidad, 2021. Línea 144) Disponible en https://www.argentina.gob.ar/generos/linea144/datos-publicos-de-la-linea-144-ano-2020
} 
Hola, te quiero pedir un gran favor, si tenés libros de poesía o recetas de cocina o de repostería ¿me podés pasar cuando puedas por celu, para escribir? Sino me voy a volver loca, voy a comprar cuadernos para escribir y matar un poco el tiempo, mi espacio es chico y no tengo mucho para hacer y escribir me va a hacer bien (Comunicación personal por whatsapp entre una de las autoras y mujer de barrio Maldonado, 15 de abril del año 2020)

Estoy acá recuperándome, estoy muy contracturada, no me podía mover, ahora me duele muy poquito, y pensando en Dios y pidiendo que todo esto se termine (Comunicación personal por whatsapp entre una de las autoras y mujer de barrio San Vicente Córdoba, 26 de abril del año 2020)

Además de llevar sus propios aislamientos en condiciones de hacinamiento, estas mujeres no dejan de afrontar triples jornadas laborales, cuidan de sus familias, salen a trabajar en changas barriales y toman laborales comunitarias, hoy de extrema necesidad para sostenerse como comunidad:

Estoy ayudando en el comedor, hay mucha gente que necesita tener un plato de comida y no puedo decir que no, este comedor me devolvió la vida, cuando más necesitaba y sé lo que se sufre no tener un plato de comida, cuando uno pasó por eso sabe realmente lo que se siente (Comunicación personal por WhatsApp entre una de las autoras y mujer de barrio Bajada San José, Córdoba, 5 de mayo del año 2020)

Si bien las desigualdades de clase se evidencian entre las mujeres, en tiempos de pandemia la sobrecarga de trabajos de cuidados, domésticos y comunitarios es un problema compartido por todas las mujeres, independientemente de la clase social. Por eso, la cuarentena desnuda la ficción de la familia nuclear, colonial: madre, padre, hija e hijo. Visibiliza que las crianzas son en soledad y con suerte, compartidas entre muchas mujeres y cuerpos feminizados: siempre entre hermanas, abuelas o mujeres del entorno. Un viejo poema Lakota decía al respecto: "Una mujer de muchos nombres. Todas las designaciones de familia: Tuwin: tía, Conchi: abuela, Hanskashi: prima, Ina: Madre, Todas honorables, Todas buenas" (Bea Medicine, poeta Lakota,s/f).

\section{Discusión: Género, clase y cuidados en el orden capitalista}

Los estudios de género y el activismo feminista demostraron que el trabajo doméstico y de los cuidados es indispensable para el orden capitalista y la reproducción de la vida en general. Sin embargo, los Estados y el mercado se niegan a reconocerlo y organizan los cuidados en torno a la explotación de las mujeres y cuerpos feminizados, desnudando al patriarcado y al capitalismo como indivisibles.

El problema de los cuidados, el uso del tiempo y el trabajo doméstico, han sido aspectos que se fueron tornando periféricos para el activismo feminista y la teoría cultural, así como ahora revitalizados a causa del aislamiento obligatorio que impulsó la pandemia, donde estos trabajos surgieron nuevamente como interrogantes para la teoría de género. 
En el caso particular de Argentina, según el INDEC (2017) 9 de cada 10 mujeres realizan trabajos de cuidado, imposible, por tanto, negarse a comprender el problema.

En efecto, cerradas las instituciones educativas y de atención o cuidado de otros/as ¿quiénes cuidan de las/os niños/as, personas mayores o con dependencias físicas en la cuarentena? Trabajos estos que las mujeres con empleos solían delegar, en parte, a otras mujeres y, otra parte, asumían como segunda jornada laboral. Todas tareas no reconocidas, pagas ni contabilizadas en la economía capitalista, que ahora se asumen a tiempo completo por todas las mujeres.

Por lo tanto, los feminismos encuentran que se debe debatir la artificial diferenciación entre esfera reproductiva y no productiva en la economía. En efecto, la distinción entre espacio de la producción y espacio de la reproducción es una trampa capitalista para que todos los ámbitos de la vida sean mercantilizados en favor del capital. Para Corina Rodríguez Enríquez (2014), el trabajo de cuidado en sentido amplio, pero principalmente pensando en el no remunerado que se realiza en el interior de los hogares, tiene como rol esencial en las economías capitalistas la reproducción de la fuerza de trabajo. De lo contrario, la fuerza de trabajo no podría reposicionarse ni mantenerse.

Sin embargo, para los economistas clásicos, este trabajo se encuentra invisibilizado y "(...) la oferta laboral se entiende como el resultado de una elección racional de las personas (individuos económicos) entre trabajo y ocio (no trabajo), determinada por las preferencias personales y las condiciones del mercado laboral (básicamente, el nivel de los salarios)" (Rodríguez Enriquez, 2014, p.37). Debido a lo cual, urge debatir la necesaria distribución y reconocimiento de las tareas domésticas y de cuidado, desarmado lo que Varela (2020) señala como falsa dicotomía entre trabajo productivo y reproductivo:

Establecer cuál es el rol del trabajo de reproducción social y su relación con el trabajo productivo implica darle la mayor de las importancias en el capitalismo, porque ayuda a comprender, entre otras cosas, el exacto punto en que género y clase se intersectan, no por casualidad, no aleatoriamente, sino en forma necesaria para que este sistema (de opresión y explotación) se reproduzca (Varela, 2020, p.75)

Asimismo, Federici (2018) desarrolla que la diferenciación entre trabajo productivo y reproductivo fue y es parte de la estrategia del capitalismo para impulsar el trabajo industrial, para que el salario sea una institución y de este modo desposeer a las/os trabajadores de su fuerza productiva. Los y las trabajadoras fueron así expropiadas/os de sus medios de vida para vender su fuerza de trabajo y ser entonces primero obrero/as y luego personas. Mercantilizada la fuerza de trabajo, las tareas consideradas reproductivas se constituyeron en pilares funcionales al capitalismo.

En consecuencia, las mujeres suman triples jornadas laborales en el mundo y más en contextos de crisis como son las guerras o las pandemias. Sobre el cuerpo de ellas recaen los cuidados y el mandato de asumirlos como tareas naturales según su género, de lo contrario son sancionadas socialmente. Realidad que se profundiza en estos 
momentos de aislamiento social obligatorio, que como mostraron las encuestas, sobrecarga la vida de las mujeres hasta el agotamiento.

En ese marco, los feminismos reposicionan el debate sobre la urgencia de generar políticas de redistribución de las responsabilidades entre familias, Estado y mercado, de modo de ganar mayor equidad en la vida de las mujeres. Intervenir en la manera en que los cuerpos de las mujeres son explotados en favor del sostenimiento del capitalismo "es un eslabón indispensable para consolidar una organización del cuidado orientada por la perspectiva de los derechos, y que resulte más justa para todos y todas" (Rodríguez Enríquez, 2014, p.23).

\section{Reflexiones finales}

Entre las mujeres de clase trabajadora, media y sectores profesionales, la cuarentena obligatoria les ha demandado horas de teletrabajo junto con la obligación para quienes tienen niñas/os en edad escolar, de acompañar la resolución de las clases desde el hogar. Ahora no sólo son cuidadoras sino también maestras, lo que afectó la organización de los espacios en la casa, los tiempos, vínculos y los trabajos domésticos recurrentes -y permanentes- de las personas del entorno. Las mujeres se ocupan de la distribución de los productos en los hogares de adultos mayores a cargo, clases domiciliarias, teletrabajo, limpieza doméstica y ayudas comunitarias. También asumen horas y horas realizando filas eternas para comprar en farmacias, supermercados y locales de limpieza. Actividades aún más complejas para mujeres de hogares monoparentales, cuando los gobiernos no permiten la circulación con niños y niñas.

En contexto de pandemia, las mujeres encuestadas deben asumir el teletrabajo, resolver el doméstico y familiar e incluso el comunitario. La primera, segunda y tercera jornada laboral se convierten en un tiempo continuo de 24 horas de trabajo intenso. Además, como muestran las cifras de femicidios y denuncias de violencia de género, el espacio considerado privado se torna más peligroso que el público para algunas mujeres, porque la violencia aumenta en tiempos de crisis económica, guerras y encierro; de hecho, en Argentina, durante el primer mes en cuarentena hubo 36 femicidios en contexto de aislamiento.

Sin embargo, desde los discursos mediáticos y en las redes sociales, insisten con circular recomendaciones de salud y entrenamientos físicos para mantener una buena "salud psíquica y física" en aislamiento. Propuestas y variedad de ofertas de actividades recreativas-físicas-artísticas para hacer en casa, desde gimnasia, yoga, danza, clases de arte, clases de meditación y terapia online. Durante todo el día se ofertan posibilidades de consumo y consejos para ser personas productivas. De repente, la medida estatal de "quédate en casa para cuidar y cuidarte del Coronavirus", paso a constituirse en mantras de superación personal, consumos ilimitados y exigencias laborales para mejorar el rendimiento. No existen propuestas que miren las problemáticas que señalamos en el artículo o que al menos las visibilicen. 
Al contrario, desde los discursos públicos se aumentan las exigencias descriptas para las mujeres, donde solo un grupo minoritario puede someterse a los mandatos del mercado y de la superación de una misma: personas de zonas urbanas, sin personas a cargo, que cuenten con salario fijo y disponibilidad de tiempo. Porque ¿cómo impactan esos mandatos en una trabajadora doméstica con salario precarizado? ¿Cómo se queda en casa una mujer que convive con su agresor? ¿Qué tiempos de recreación tiene una madre a tiempo con cuidados a tiempo completo? Una vez más, el enfoque interseccional nos muestra las múltiples realidades que nos atraviesan y nos llevan a prestar especial atención a la categoría de clase pues, tal como sostiene Skeggs (2019), la categoría mujer es siempre el producto de procesos que incluyen lo económico.

A la sociedad patriarcal (y también a la ciencia patriarcal y androcéntrica) no le es conveniente el debate sobre el tiempo que las mujeres dedican a estos trabajos ni sus problemáticas, excepto que alguno de éstos dañe la "moral femenina". Como explica Gorbán (2019):

"No importan las mujeres y sus experiencias subjetivas salvo que su accionar pueda dañar el tejido social, la organización y la integración. Si las mujeres se ausentan de esos roles socialmente designados para ellas, no amenazan su integridad moral, sino la del conjunto social" (p.16).

Como hemos podido ver, el patriarcado establece relaciones de dominación y de poder entre los cuerpos que habitan la sociedad. Las mujeres y aquellas corporalidades feminizadas están en posiciones de subordinación, ocupándose de aquellos roles/tareas/trabajos más explotados, menos reconocidos y peores pagos. Paradojalmente, son esas tareas de cuidado y reproducción centrales para la sostenibilidad de la vida.

En este contexto inesperado e incierto al que nos obliga la pandemia, se perpetúa la lógica capitalista de exigir productividad contante a las trabajadoras, sin atender al ambiente hostil, la sobrecarga de jornadas laborales, las dificultades emocionales que implican atravesar una crisis sanitaria global, que nos atraviesa radicalmente a todas y todos. Por eso, como dijera Mariana Enríquez (2020) en una entrevista reciente:

Me rebelo ante esta demanda de productividad cuando sólo siento desconcierto. Poder, poder, poder, qué podemos hacer, qué podemos pensar. En una charla con una amiga le dije, sinceramente: "pienso corto". Es verdad. No encuentro reflexiones (...) Todas las preguntas me dejan muda. Todos los traumas, todos los miedos, no sé qué va a pasar con la humanidad, cómo pensar en "humanidad", qué significa eso, por qué tenemos que pensar en la nueva normalidad si la pandemia recién empieza, al menos en la Argentina" (p.1).

Así, consideramos urgente la redistribución y reconocimiento de los trabajos de cuidado y domésticos que realizamos las mujeres, como base para pensar en un orden social más justo y equitativo. Esta pandemia puso en el centro de la escena una realidad constante del capitalismo patriarcal: las desigualdades entre varones y cuerpo 
Revista Punto Género N ․ㅜ 15. Junio de 2021

ISSN 0719-0417 / 89-113

feminizados en relación con los trabajos que se llevan adelante en el ámbito de lo considerado privado o íntimo y que es tan necesario para sostener el sistema como aquel llamado trabajo productivo. Como sostiene la clásica consigan del paro de mujeres del 8 de marzo de cada año: "Si las mujeres paramos, se para el mundo".

\section{Bibliografía}

Arriagada, Irma \& Todaro, Rosalba (2012): El papel de las migrantes peruanas en la provisión de cuidados en Chile. Santo Domingo, República Dominicana: ONU Mujeres.

Batthyány, Karina (2010): Envejecimiento, cuidados y género en América Latina. Seminario internacional Experiencias internacionales y propuestas para consolidar la red nacional de cuidado de las personas adultas mayores en Costa Rica. Recuperada de: http://www.cepal.org/dds/noticias/paginas/3/41413/batthyany.pdf

Basaglia, Franca (1983): Mujer, locura y sociedad. México: Universidad Autónoma de Puebla.

Benet, Marta; Merhy, Elías \& Pla, Margarida (2016): Devenir cartógrafa. Athenea Digital 16(3):: 229-243. DOI: https://doi.org/10.5565/rev/athenea.1685

Bidaseca, Karina, Aragão Guimarães, Michelly, Brighenti, Maura \& Ruggero, Santiago (2021): Diagnóstico de la situación de las mujeres rurales y urbanas, y disidencias en el contexto de COVID-19. CONICET. Disponible en: https://www.conicet.gov.ar/wpcontent/uploads/resumen ejecutivo mujeres y covid - mincyt-conicet mingen.pdf

Blanco, Mercedes (2012): ¿Autobiografía o autoetnografía? Desacatos no.38. Recuperada de: $\quad$ http://www.scielo.org.mx/scielo.php?pid=S1607$\underline{\text { 050X2012000100012\&script=sci arttext }}$

Burin, Mabel (2013): El modelo hegemónico de salud no tiene cómo codificar lo que nos sucede a las mujeres. Comunicación para la lgualdad. Recuperado de: 
Revista Punto Género N.ำ 15. Junio de 2021

ISSN 0719-0417 / 89-113

https://comunicarigualdad.com.ar/el-modelo-hegemonico-de-salud-no-tienecomo-codificar-lo-que-nos-sucede-a-las-mujeres/

Burín, Mabel (2012): Laberintos de cristal en la carrera laboral de las mujeres. El rol de las mentoras. OEl. Recuperado de: www.oei.es/historico/congresoctg/memoria/ pdf/Mburin.pdf

Carrasco, Cristina (2001): La sostenibilidad de la vida humana: ¿un asunto de mujeres? Porto Alegre: Veraz Comunicação.

Carrasco, Cristina \& Domínguez, Marius (2002): Género y usos del tiempo: nuevos enfoques metodológicos. Revista Economía Crítica.Núm. 1 Pág. 129-152.

Castañeda, Patricia (2012): Investigación feminista: caracterización y prospectiva. En Montiel, Edgar (2014): Pensar un mundo durable para todos. (pp. 151-164): Guatemala: UNESCO.

Chant, Sylvia (2005): ¿Cómo podemos hacer que la "feminización de la pobreza" resulte más relevante en materia de políticas? ¿Hacia una "feminización de la responsabilidad y la obligación"? En: Mora, L.; Moreno Ruiz, M. J.; Rohrer, T. (Ed.):: Cohesión social, políticas conciliadoras y presupuesto público: una mirada desde el género. (pp. 201-234):. México: Unfpa,

De Sousa Santos, Boaventura (2020): La cruel pedagogía del virus. Ciudad Autónoma de Buenos Aires: CLACSO.

Del Río,Sira (2004): La crisis de los cuidados: precariedad a flor de piel. Rebelión Economía, No. 1 , Recuperado de: https://www.rebelion.org/hemeroteca/economia/040308sira.htm

Enríquez, Mariana (2020): La Ansiedad. Revista de la Universidad de México. Cultura Unam. México. Recuperado de: https://www.revistadelauniversidad.mx/articles/41725f69-40a0-4229-b7d28bc714717cd2/la-ansiedad 
Revista Punto Género N ․ㅜ 15. Junio de 2021

ISSN 0719-0417 / 89-113

Ferraroti, Franco (1983): Biografía y ciencias sociales. San José: Facultad Latinoamericana de Ciencias Sociales.

Federici, Silvia (2018): El patriarcado del salario. Críticas feministas al marxismo. Madrid: Traficantes de Sueños.

Friedan, Betty (2016 [1963]): La mística de la feminidad. Barcelona: Feminismos.

Gómez Rubio, Constanza; Ganga León, Catalina \& Rojas Paillalef, Wilson (2017): Desigualdades de género en trabajos de cuidados familiar y no remunerado: una revisión Iberoamericana. Revista Punto Género №7. Recuperada de: https://revistahistoriaindigena.uchile.cl/index.php/RPG/article/view/46275/4827 $\underline{7}$

Gorbán, Débora (2019): Prólogo: Un encuentro con una académica inglesa. En: Skeggs, Beverley (2019): Mujeres respetables: clase y género en los sectores populares. Los Polvorines: Universidad Nacional de General Sarmiento.

Guerrero Muñoz, Joaquín (2014): El valor de la auto-etnografía como fuente para la investigación social: del método a la narrativa. AZARBE, Revista Internacional De Trabajo Social y Bienestar. Recuperada de: https://revistas.um.es/azarbe/article/view/19869

INDEC (2017): Encuesta Permanente de Hogares. Disponible en https://www.indec.gob.ar/indec/web/Institucional-Indec-BasesDeDatos

Jelin, Elizabeth (2013): Políticas de cuidado. Debates conceptuales en torno al cuidado. La dimensión de género en las políticas de cuidado. Buenos Aires: CIPPEC.

Jónasdottir Anna (2011): ¿Qué clase de poder es "el poder del amor”? Sociológica, 26, número

74.

Recuperada

de: http://www.scielo.org.mx/pdf/soc/v26n74/v26n74a8.pdf Jónadottir, Anac (1994): Why Women Are Oppressed.Filadelfia: Temple University Press. 
Revista Punto Género N.ำ 15. Junio de 2021

ISSN 0719-0417 / 89-113

Méndez, Georgina; López, Juan; Marcos, Sylvia \& Osorio, Carmen (coord..): (2013): Senti-pensar el género. Perspectivas desde los pueblos originarios, Guadalajara, La Casa del Mago.

Merhy, Elías (2006): Salud: cartografía del trabajo vivo. Buenos Aires: Editorial Lugar.

ONU (2020): La pandemia expone y explota desigualdades de todo tipo, incluida la de género. ONU. Recuperado de: https://www.un.org/es/coronavirus/articles/guterres-covid-19-exponedesigualdad-genero

Ministerio de Economía (2020): Los cuidados, un sector económico estratégico. Medición del aporte del Trabajo Doméstico y de Cuidados no Remunerado al Producto Interno Bruto. Informe disponible en: https://www.argentina.gob.ar/sites/default/files/los cuidados un sector economico estrategico 2.pdf

Ramonet, Ignacio (29 de abril de 2020): Coronavirus: La pandemia y el sistema-mundo. Diario Página 12. Recuperado de: https://www.pagina12.com.ar/262989coronavirus-la-pandemia-y-el-sistema-mundo

Ranzani, Oscar (2020): Coronavirus: cómo impacta la cuarentena en los consultorios psicológicos. Diario Página 12. Recuperado de: https://www.pagina12.com.ar/260089-coronavirus-como-impacta-lacuarentena-en-los-consultorios- $p$

Razavi, Shahra (2007): The Political and Social Economy of Care in a Development Context: Conceptual Issues, Research Questions and Policy Options. Génova: UNRISD.

Rich, Adrienne (2019): Nacemos de mujer. La maternidad como experiencia e institución. Madrid: Traficante de Sueños. 
Revista Punto Género N. 15. Junio de 2021

ISSN 0719-0417 / 89-113

Rodríguez Enríquez, Corina María (2014): El trabajo de cuidado no remunerado en Argentina: un análisis desde la evidencia del Módulo de Trabajo no Remunerado. Buenos Aires: ELA.

Segato, Rita (2019): ¡Ningún patriarcón hará la revolución! Reflexiones sobre las relaciones entre capitalismo y patriarcado. En: Karin Gabbert y Miriam Lang (Edit.): ¿Cómo se sostiene la vida en América Latina? Feminismos y reexistencias en tiempos de oscuridad. Quito: Fundación Rosa Luxemburg/Ediciones Abya-Yala

Skeggs, Beverley (2019): Mujeres respetables: clase y género en los sectores populares. Los Polvorines: Universidad Nacional de General Sarmiento.

Varela, Paula (2020): La reproducción social en disputa:un debate entre autonomistas y marxistas. ARCHIVOS de historia del movimiento obrero y la izquierda. Año VIII, $\quad n^{\circ} \quad 16, \quad$ pp. 71-92. Recuperado de: https://www.archivosrevista.com.ar/numeros/index.php/archivos/article/view/24 $\underline{1 / 236}$ 